\title{
The glycaemic index: importance of dietary fibre and other food properties
}

\author{
Inger Björck* and Helena Liljeberg Elmståhl \\ Department of Applied Nutrition and Food Chemistry, Centre for Chemistry and Chemical Engineering, Lund University, \\ PO Box 124, SE-221 00 Lund, Sweden
}

\begin{abstract}
An increasing body of evidence suggests that a low-glycaemic-index (GI) diet has a therapeutic as well as a preventive potential in relation to the insulin resistance syndrome. The implementation of a low-GI diet, however, will require an extended list of low-GI foods to be available on the market. The tailoring of low-GI bread products offers a particular challenge due to their generally high GI and abundance in the diet. Low-GI bread products can be tailored by, for example, enclosure of cereal kernels, sourdough fermentation and/or addition of organic acids, or use of cereal genotypes with elevated contents of amylose or $\beta$-glucans. Low-GI cereal foods appear to vary in effect on 'second-meal' glucose tolerance in healthy subjects. In addition to the slowrelease properties of such foods, the content of dietary fibre appears to play a role. The low glycaemia to starch in a pasta breakfast (GI 54) promoted a higher glucose tolerance and lowered triacylglycerol levels at a standardized lunch ingested $4 \mathrm{~h}$ later, compared with a white-wheatbread breakfast (GI 100). The metabolic benefits of the low GI properties per se have been demonstrated also in the longer term. Thus, a reduction in dietary GI improved glucose and lipid metabolism and normalized fibrinolytic activity in type 2 diabetics, while maintaining a similar amount and composition of dietary fibre. However, the higher dietary fibre content frequently associated with low-GI foods may add to the metabolic merits of a low-GI diet. Consequently, a low-GI barley meal rich in dietary fibre (GI 53) improved glucose tolerance from evening meal to breakfast, whereas an evening meal with pasta had no effect (GI 54). The exchange of common high-GI bread for low-GI high-fibre bread, as the only dietary modification, improved insulin economy in women at risk of type 2 diabetes. These results are in accordance with epidemiological evidence of a reduced risk of type 2 diabetes with a low-GI diet rich in cereal fibre. It is concluded that low-GI cereal foods developed should preferably be rich in dietary fibre.
\end{abstract}

Glycaemic response: Product tailoring: Diabetes mellitus: Dietary fibre

Diseases related to insulin resistance are common causes of death in Western societies, and the current increase in type 2 diabetes is being referred to as an epidemic. During the last 10 years an important number of studies have identified a low-glycaemic-index (GI) diet as beneficial in relation to the insulin-resistance syndrome. Several semi-long-term dietary interventions are available for healthy subjects and for subjects with metabolic disease. With a few exceptions, these studies have shown that a low-GI diet not only improves certain metabolic consequences of insulin resistance, but also reduces insulin resistance per se (Del Prato et al. 1994). In addition to improvements in glucose and lipid metabolism (Jenkins et al. 1987; Brand et al. 1991; Järvi et al. 1999) there are indications of improvements in the fibrinolytic activity (Järvi et al. 1999), suggesting a beneficial role in diabetes and cardiovascular disease. Based on this evidence, the Food and
Agriculture Organization/World Health Organization (1998) expert consultation on dietary carbohydrates strongly advocates the relevance of the GI concept, in particular for subjects with impaired glucose tolerance.

In relation to mechanisms for the metabolic advantages of low-GI foods, these may derive from the slow-release properties in the upper gastrointestinal tract, and in particular to the lowered insulin demand (Jenkins et al. 1990). Another possible mechanism relates to their generally higher content of indigestible carbohydrates, for example, dietary fibre and resistant starch (RS), which increases the fermentative activity in the colon. Consequently, propionic acid has been implicated as a moderator of hepatic glucose (Venter et al. 1990) and lipid metabolism (Wolever et al. 1989).

The therapeutic value of a low-GI diet in diabetes has been demonstrated in both type 1 and type 2 patients (Brand 
Miller, 1994). Dietary interventions with low-GI foods thus appear to lower the glycosylated haemoglobin fraction HbA1c and the incidence of hypoglycaemic episodes in juvenile (Gilbertsson et al. 2001) and maturity-onset diabetes (Giacco et al. 2000). However, in some of the semilong-term metabolic studies performed the low-GI regimens are characterised by a higher dietary fibre content (Giacco et al. 2000), making it difficult to assign the beneficial effects entirely to the low GI properties per se. With the purpose of addressing this issue, an intervention study was performed in type 2 diabetics where differences in GI between the high- and low-GI diets were achieved in the absence of differences in nutrient composition (Järvi et al. 1999). The GI differences between test periods were obtained by modifying the structural features of the foods; thus maintaining approximately identical amount and composition of dietary fibre in the low- and high-GI dietary periods. Apart from the facilitated control of blood glucose and lowered LDL-cholesterol, a dramatic lowering of plasminogen activator inhibitor 1 levels was observed during the low-GI period. These data suggest that the GI characteristics of the diet per se are indeed important, and that the low-GI period normalized a risk factor for thrombosis, in the absence of a change in dietary fibre intake. It should be pointed out, however, that even in the absence of a difference in dietary fibre low-GI foods frequently contain a higher amount of RS (Björck et al. 2000), which may add to the metabolic advantages of low-GI diets.

As for the preventive potential, prospective studies indicate that a low-GI diet, and/or a diet rich in whole-grain products reduce the risk of type 2 diabetes (Salmerón et al. $1997 a, b)$. There are also data to suggest a negative correlation between serum HDL-cholesterol and dietary GI (Frost et al. 1999). In fact, in the study by Frost et al. (1999), dietary GI was a stronger predictor of serum HDLcholesterol than dietary fat. Moreover, there is evidence that a low-GI diet may reduce the risk of myocardial infarction in women (Liu et al. 2000).

The findings of Salmerón et al. $(1997 a, b)$ raise the question whether dietary fibre, or at least cereal fibre, could be a more important preventive factor than the GI characteristics, and the most commonly consumed wholegrain products, such as flour-based bread and breakfast cereals, have high, rather than low, GI (Foster-Powell et al. 2002).

Accumulating data thus substantiate the therapeutic and preventive efficacy of low-GI foods in general in relation to the metabolic syndrome, and that cereal fibre may have a preventive effect. However, the implementation of the GI concept in dietary advice will require a much wider range of low-GI products. In particular, there is a shortage of low-GI cereal foods. On the basis of the experimental and epidemiological evidence referred to earlier, the development of low-GI high-fibre cereal products seems particularly relevant from a metabolic perspective.

\section{Tailoring of low-glycaemic-index cereal foods with focus on bread products}

In most European countries, bread constitutes a major source of dietary carbohydrates. Consequently, there is a need for new technologies that can be used to modulate the GI of bread, with the focus on wholegrain bread. One obvious alternative would be to encourage the use of more or less intact cereal kernels and kernel-based breads are usually characterised by a low GI (Liljeberg et al. 1992; Liljeberg \& Björck, 1994). The mechanism for this effect is an obstructed amylolysis, due to botanical encapsulation of starch and/or a limited extent of starch swelling. However, the challenge for the food industry will be to find technologies that can be used to lower the GI of meal-based bread, since the difference in GI properties between wholemeal bread from common cereals and white bread is usually marginal (Jenkins et al. 1986; Liljeberg et al. 1992).

\section{Potential of barley genotypes}

In a study by Åkerberg et al. (1998) wholegrain barley flours with different amylose contents were subjected to conventional baking $\left(45 \mathrm{~min}, 200^{\circ}\right)$, or low-temperature long-duration baking conditions $\left(20 \mathrm{~h}, 120^{\circ}\right)$, i.e. pumpernickel-baking conditions. An increased holding temperature with a wet temperature of $100^{\circ}$, as during low-temperature long-duration baking, promotes growth of crystalline amylose, a phenomenon known as annealing (Eerlingen et al. 1993). Using high-amylose barley flour and these baking conditions it was possible to reduce the GI predicted from the in vitro rate of starch hydrolysis and the measured GI by approximately $30 \%$ (Table 1). It was also found that baking at annealing conditions increased RS content to a high level (10\% on total starch basis). The use of highamylose barley thus makes it possible to produce a low-GI bread from flour-based ingredients. Moreover, such bread products can be produced with elevated contents of RS, with potential beneficial effects on colonic health (Scheppach et al. 1992).

The development of whole-grain low-GI foods could also involve cereal genotypes with high levels of viscous fibre. One example of such a genotype is Prowashonupana barley, which contains as much as $190 \mathrm{~g} \beta$-glucans $/ \mathrm{kg}$. Such flour was included at different levels in mixtures with white wheat and baked into flat bread (E Rossi, H Elmståhl, H Larsson and I Björck, unpublished results). The levels were 0 (i.e. pure wheat), 350, 500 and $750 \mathrm{~g}$ Prowashonupana barley $/ \mathrm{kg}$. In parallel with the measurement of GI in healthy subjects, the fluidity index of the corresponding in vitro enzymic digesta was measured using a very simple Bostwick consistometer. The digesta were prepared by incubating the products with enzymes in simulated in vivo conditions (Granfeldt et al. 1992). The lower the fluidity index, the higher the viscosity. The results showed that the inclusion of Prowashonupana flour lowered the fluidity index of the digesta, and as a consequence lowered GI compared with the flat bread with no added Prowashonupana flour by 30,40 and $50 \%$ at the 350,500 and $750 \mathrm{~g} / \mathrm{kg}$ levels of inclusion, respectively. By including Prowashonupana flour in flat bread it was thus possible to substantially lower GI compared with white bread or a product containing $500 \mathrm{~g}$ common barley/ $\mathrm{kg}$ in a mixture with white wheat. However, the commercial dehulling and desprouting procedure must be carefully controlled to maintain the viscosity of the $\beta$-glucans, and with some 
Table 1. Effect of barley genotype and baking conditions on resistant starch (RS) content, in vitro starch hydrolysis rate (hydrolysis index; HI) and predicted and determined glycaemic index (GI) (from Granfeldt et al. 1992; Åkerberg et al. 1998) (Values are means with their standard errors of the means)



a, b, c, d, e, f, g Mean values with unlike superscript letters were significantly different $(P<0.05)$.

${ }^{*}$ Content on a total starch basis.

†Wholemeal barley-white wheat $(70: 30, \mathrm{w} / \mathrm{w})$

commercial batches, inclusion of Prowashonupana at a level of $500 \mathrm{~g} / \mathrm{kg}$ failed to affect either the fluidity or the glycaemic properties of the bread. Consequently, the amount of $\beta$-glucan added to a product may be a poor predictor of the glycaemic effect associated with a processed food product. However, the study shows that the GI of barley bread containing variable amounts of $\beta$-glucans can be predicted with good accuracy from measurement of fluidity in an in vitro system. It also demonstrates a potential for cereal genotypes rich in $\beta$-glucans.

\section{Sourdough baking and addition of organic acids}

Another process that could be used to lower the GI of wholegrain bread is sourdough fermentation. In a study in which white bread was used as a vehicle for organic acids, white bread with vinegar was given in a breakfast meal to healthy subjects, using white bread with no acid as a control (Liljeberg \& Björck, 1998). The amount of acetic acid added was selected to mimic the level reached during sourdough fermentation, and the presence of acetic acid lowered the postprandial metabolic responses (GI 64, insulin index 65).

A lowered rate of glucose delivery to the blood might be secondary to a lowered rate of gastric emptying. Paracetamol is used as a marker of gastric emptying, as it is not absorbed in the stomach but instead rapidly absorbed in the upper duodenum. The appearance of paracetamol in the blood was slower following ingestion of the bread with acetic acid, suggesting that this acid delays gastric emptying rate (Liljeberg \& Björck, 1998). When added to wholegrain barley bread lactic acid also appears to lower glycaemia in healthy subjects, when tested at a level similar to that achieved using a homo-fermentative starter culture (Liljeberg et al. 1995). However, in contrast to acetic acid and sodium propionate, the lowered glycaemia with lactic acid-containing bread could not be assigned to a lowered gastric emptying rate using paracetamol as a marker (Fig. 1). Instead, the lowering of GI could be predicted from measurement of the rate of in vitro starch hydrolysis, suggesting

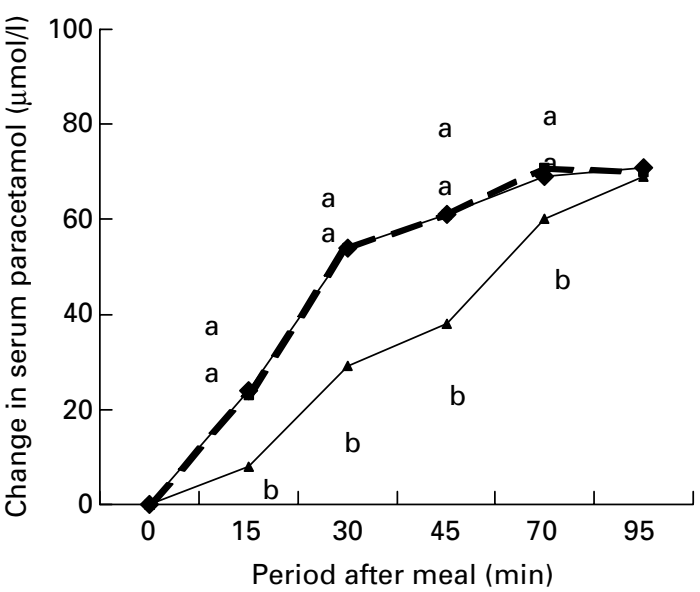

Fig. 1. Serum paracetamol responses in healthy subjects following a breakfast meal with wholegrain barley bread alone $(-\downarrow)$ or with the addition of lactic acid $(\mathbf{-}-\mathbf{-})$ ) or sodium propionate $(\boldsymbol{\Delta}-\mathbf{A}) \cdot$, a,b Mean values with unlike superscript letters were significantly different $(P<0.05)$. (From Liljeberg \& Björck, 1996.)

that lactic acid interferes with the digestive process. In order to investigate the mechanism for the prohibitive effect on amylolysis, wheat starch-gluten mixtures were treated with lactic acid before or after heat treatment at simulated baking conditions and the enzyme availability tested using an in vitro method previously shown to predict GI with good accuracy (Granfeldt et al. 1992). The presence of lactic acid during heat treatment lowered the predicted GI, but only in the presence of gluten (Östman et al. 2002). A decrease in $\mathrm{pH}$ per se had no impact. Furthermore, the addition of lactic acid after heat treatment was not effective, suggesting that lactic acid does not act as a classical enzyme inhibitor. Homogenisation of the mixture removed the enzyme barrier, and it is possible that lactic acid induces interactions between starch and gluten, leading to reduced starch availability. 
Thus, sourdough fermentation or the addition of organic acids represent other methods that can be used to lower the GI of bread products.

\section{Importance of glycaemic index properties $v$. dietary fibre content}

\section{Second-meal effects}

Which types of low-GI cereals are preferable, and could there be differences in metabolic advantages between lowGI products? One mechanism that could account for the metabolic benefits of a low-GI diet might be secondary to the so-called 'second-meal phenomenon'. The finding that a low-GI meal improves glucose tolerance to the following meal was reported first by Jenkins et al. (1980). The phenomenon can be seen from breakfast to lunch (Jenkins et al. 1982), but also from the evening meal to breakfast (Wolever et al. 1988). In a study by Liljeberg et al. (1999) the effects of three different cereal breakfasts on glucose tolerance at a standardized lunch ingested $4 \mathrm{~h}$ later was measured in healthy subjects (Table 2). The test breakfasts had GI in the lower range (from 52 to 64) and consisted of pasta, a fibre-rich mixed barley meal or white bread with vinegar. A breakfast consisting of a carbohydrate-equivalent amount of white bread was used as reference. In the case of the spaghetti and the mixed barley-based breakfast, the lunch produced only 60 or $70 \%$ of the corresponding glycaemic response after the reference breakfast. The pasta breakfast also significantly lowered the insulin response at lunch $(P<0.05)$. In contrast, no significant effect was noted at lunch in the case of the breakfast with white bread + vinegar. The net increment in glycaemia when commencing the lunch in the case of the pasta and the barley breakfasts was an indicator of a prolonged absorption. This finding might suggest that in addition to low GI properties, as calculated by the 90 (Liljeberg \& Björck, 1998) or $120 \mathrm{~min}$ (Wolever et al. 1991) glucose areas under the curves, the presence of a late glycaemic response may promote a $4 \mathrm{~h}$ second-meal effect. It seems that even though the dietary fibre and RS contents are low (Liljeberg et al. 1999), the pasta breakfast is capable of lowering glucose tolerance at lunch (Liljeberg et al. 1999; Liljeberg \& Björck, 2000). The pasta breakfast also lowered triacylglycerol levels after the standardized lunch (Liljeberg \& Björck, 2000). Similar

Table 2. Incremental blood glucose and insulin areas under the curve (AUC) in healthy human subjects after a standardized lunch meal following various cereal breakfasts

\begin{tabular}{|c|c|c|c|c|}
\hline & \multicolumn{2}{|c|}{ Breakfast } & \multicolumn{2}{|c|}{$\begin{array}{c}\text { Standardized lunch } \\
\text { incremental (AUC) (\%) }\end{array}$} \\
\hline & GI & II & Glucose & Insulin \\
\hline White bread & 100 & 100 & 100 & 100 \\
\hline Spaghetti & 52 & 42 & $64^{*}$ & $69^{*}$ \\
\hline $\begin{array}{l}\text { Barley, rich in amylose } \\
\text { and } \beta \text {-glucans }\end{array}$ & 60 & 70 & $72^{*}$ & 82 NS \\
\hline White bread + vinegar & 64 & 65 & 79 NS & 79 NS \\
\hline
\end{tabular}

GI, glycaemic index; II, insulin index.

Mean values were significantly different from those for subjects receiving white bread as breakfast: ${ }^{*} P<0.05$. information may be useful in the development of cereal products with optimal carbohydrate release profiles. The finding that a low GI per se has a beneficial effect on glucose tolerance is in agreement with results from a semilong-term intervention in subjects with non-insulindependent diabetes mellitus (Järvi et al. 1999), in which a lowering of dietary GI, in the absence of difference in dietary fibre, markedly improved metabolic variables relating to insulin resistance.

In another study the effects of three evening meals containing cereal on glucose tolerance at a following standardized white-bread breakfast were evaluated (Y Granfeldt, $\mathrm{W}$ Xaomei and I Björk, unpublished results). The evening meals were served at 22.00 hours to healthy subjects and consisted of white bread or two low-GI meals (spaghetti GI 54, insulin index 53; barley kernels GI 53, insulin index 49). The low-GI evening meals were thus matched with respect to GI and insulin index, but were very different in the content of indigestible carbohydrates, i.e. dietary fibre and RS. When compared with the white-bread evening meal, only the low-GI barley evening meal, rich in indigestible carbohydrates, improved glucose tolerance the following morning. The reduction in glucose and insulin areas under the curve at the standardized breakfast meal was approximately $25 \%$. No blunting effect was noted following pasta as the evening meal, which was in contrast to the finding that pasta markedly improved glucose tolerance from breakfast to lunch (Liljeberg et al. 1999; Liljeberg \& Björck, 2000). A possible mechanism could be that the barley meal promotes a higher fermentative activity in the colon, which may act to suppress non-esterified fatty acid levels, and hence improve glucose tolerance $10 \mathrm{~h}$ later, i.e. at the time of the breakfast meal. It has also been reported that an evening meal with barley, but not rice, improves glucose tolerance and lowers non-esterified fatty acids the following morning (Thorburn et al. 1993). On the basis that this overnight phenomenon contributes to the long-term benefits of a lowGI diet, the new generation of cereal products should, therefore, not only have a low GI and a slow release profile of the digestible carbohydrates fraction, but preferably also be rich in indigestible and fermentable carbohydrates. This added value of low-GI cereal products rich in dietary fibre could provide one mechanism for the epidemiological evidence that a high content of cereal fibre, in addition to a low glycaemic load, protect against development of type 2 diabetes (Salmerón et al. 1997a,b).

\section{Metabolic potential of low-glycaemic-index fibre-rich bread products in women at risk of type 2 diabetes}

Another important issue in relation to product tailoring and optimisation of dietary GI relates to the magnitude of the dietary change necessary to achieve the required metabolic effect. To address this question, the semi-long-term potential of modulating only the GI of the bread products was studied in women at risk of type 2 diabetes (H Liljeberg Elmståhl, A Frid, L Groop and I Björk, unpublished results). The bread products were commercial high-GI products or two types of modulated low-GI bread, one light and one dark. Both low-GI bread products were based on intact rye kernels and baked using sourdough fermentation. The 
lighter bread contained fewer intact kernels, and instead had added oat B-glucans. Both the light and the dark bread had similar GI of about 55. The commonly-consumed high-GI bread products were thus replaced by experimental bread products with lower GI and a higher content of indigestible carbohydrates. The test subjects were women (about 31 years of age) with a history of gestational diabetes. These women showed a genetic disposition for type 2 diabetes during pregnancy, with a high risk of developing diabetes later in life. An oral glucose tolerance test was performed before inclusion in the study. Subjects diagnosed with diabetes were excluded, and only those with impaired glucose tolerance were recruited. Seven of the eight women participants completed the study. The bread was included in the breakfast, lunch and late-evening meals, and the amount of carbohydrates provided during the two test periods was standardized for each individual. A crossover design was used, with 3-week intervention periods and a 3-week washout period. The glucose and insulin responses to an intravenous glucose challenge were measured before and after each intervention period. No significant difference was noted in the $1 \mathrm{~h}$ insulin areas under the curve over the intervention period with the high-GI bread. In contrast, all women displayed a decrease in insulin response over the period with the low-GI bread. The mean decrease was substantial (about $40 \%$ ). No differences were noted in the corresponding blood glucose responses to the intravenous glucose challenge, and the results indicated that replacing the usual high-GI bread with the modified low-GI high-fibre bread improved insulin economy in women at risk of type 2 diabetes. It remains to be established whether these low-GI bread products may actually postpone development of type 2 diabetes. These experimental data are, however, in line with epidemiological evidence of a lowered risk for type 2 diabetes with a low-GI diet rich in cereal fibre (Salmerón et al. $1997 a, b)$.

\section{References}

Åkerberg A, Liljeberg H \& Björck I (1998) Effects of amylose/amylopectin ratio and baking conditions on resistant starch formation and glycaemic indices. Journal of Cereal Science 28, 71-80.

Björck I, Liljeberg H \& Östman E (2000) Low glycaemic-index foods. British Journal of Nutrition 83, 149S-155S.

Brand J, Colagiuri S, Crossman S, Allen A, Roberts D \& Truswell S (1991) Low-glycemic index foods improve long term glycemic control in NIDDM. Diabetes Care 14, 95-101.

Brand Miller JC (1994) Importance of glycemic index in diabetes. American Journal of Clinical Nutrition 59, 747S-752S.

Del Prato S, Leonetti F, Simonson DC, Sheehan P, Matsuda M \& DeFronzo RA (1994) Effect of sustained physiologic hyperinsulinaemia and hyperglycaemia on insulin secretion and insulin sensitivity in man. Diabetologia 37, 1025-1035.

Eerlingen RC, Crombez M \& Delcour JA (1993) Enzyme-resistant starch. I. Quantitative and qualitative influence of incubation time and temperature of autoclaved starch on resistant starch formation. Cereal Chemistry 70, 339-344.

Food and Agriculture Organization/World Health Organization (1998) Carbohydrates in Human Nutrition: Report of a Joint FAO/WHO Expert Consultation. FAO Food and Nutrition Paper no. 66. Rome: FAO.
Foster-Powell K, Holt S \& Brand-Miller J (2002) International table of glycemic index and glycemic load values: 2002. American Journal of Clinical Nutrition 76, 5-56.

Frost G, Leeds AA, Doré CJ, Madeiros S, Brading S \& Dornhorst A (1999) Glycaemic index as a determinant of serum HDLcholesterol concentration. Lancet 353, 1045-1048.

Giacco R, Parillo M, Rivallese A, Lasorella G, Giacco A, D'Episcopo L \& Riccardi G (2000) Long-term dietary treatment with increased amount of fiber-rich low-glycemic index natural foods improves blood glucose control and reduces the number of hypoglycemic events in type 1 diabetic patients. Diabetes Care 23, 1461-1466.

Gilbertsson H, Brand Miller J, Thorburn A, Evans S, Chondros P \& Werther G (2001) The effect of flexible low glycemic index dietary advice versus measured carbohydrate exchange diets on glycemic control in children with type 1 diabetes. Diabetes Care 24, 1137-1143.

Granfeldt Y, Björck I, Drews A \& Tovar J (1992) An in vitro procedure based on chewing to predict metabolic response to starch in cereal and legume products. European Journal of Clinical Nutrition 46, 649-660.

Järvi AE, Karlström BE, Granfeldt YE, Björck IME, Asp N-G \& Vessby BOH (1999) Improved glycemic control and lipid profile and normalized fibrinolytic activity on a lowglycemic index diet in type 2 diabetic patients. Diabetes Care 22, $10-18$.

Jenkins DJ, Wolever TM, Jenkins AL, Giordano C, Giudici S, Thompson LU, Kalmusky J, Josse RG \& Wong GS (1986) Low glycemic response to traditionally processed wheat and rye products: bulgur and pumpernickel bread. American Journal of Clinical Nutrition 43, 516-520.

Jenkins DJ, Wolever TM, Kalmusky J, Guidici S, Giordano C, Patten R, Wong GS, Bird JN, Hall M, Buckley G, Csima A \& Little JA (1987) Low-glycemic index diet in hyperlipidemia: use of traditional starchy foods. American Journal of Clinical Nutrition 46, 66-71.

Jenkins DJ, Wolever TM, Nineham R, Sarson DL, Bloom SR, Ahern J, Alberti KG \& Hockaday TD (1980) Improved glucose tolerance four hours after taking guar with glucose. Diabetologia 19, 21-24.

Jenkins DJ, Wolever TM, Ocana AM, Vuksan V, Cunnanen SC, Jenkins M, Wong GS, Singer W, Bloom SR, Blendis LM \& Josse RG (1990) Metabolic effects of reducing rate of glucose ingestion by single bolus versus continuous sipping. Diabetes 39, $775-781$.

Jenkins DJ, Wolever TM, Taylor RH, Griffiths C, Krzeminska K, Lawrie JA, Bennett CM, Goff DV, Sarson DL \& Bloom SR (1982) Slow release dietary carbohydrate improves second meal tolerance. American Journal of Clinical Nutrition 35, 1339-1346.

Liljeberg H \& Björck I (1994) Bioavailability of starch in bread products. Postprandial glucose and insulin responses in healthy subjects and in vitro resistant starch content. European Journal of Clinical Nutrition 48, 151-163.

Liljeberg H \& Björck I (1996) Delayed gastric emptying rate as a potential mechanism for lowered glycemia after eating sourdough bread: studies in humans and rats using test products with added organic acids or an organic salt. American Journal of Clinical Nutrition 64, 886-893.

Liljeberg H \& Björck I (1998) Delayed gastric emptying rate may explain improved glycaemia in healthy subjects to a starchy meal with added vinegar. European Journal of Clinical Nutrition 52, 368-371.

Liljeberg H \& Björck I (2000) Effects of a low-glycaemic index spaghetti meal on glucose tolerance and lipaemia at a subsequent meal in healthy subjects. European Journal of Clinical Nutrition $\mathbf{5 4}, 24-28$. 
Liljeberg H, Granfeldt Y \& Björck I (1992) Metabolic responses to starch in bread containing intact kernels versus milled flour. European Journal of Clinical Nutrition 46, 561-575.

Liljeberg H, Lönner C \& Björck I (1995) Sourdough fermentation or addition of organic acids or corresponding salts to bread improves nutritional properties of starch in healthy humans. Journal of Nutrition 125, 1503-1511.

Liljeberg HGM, Åkerberg AKE \& Björck IME (1999) Effect of the glycemic index and content of indigestible carbohydrates of cereal-based breakfast meals on glucose tolerance at lunch in healthy subjects. American Journal of Clinical Nutrition 69, 647-655.

Liu S, Willett W, Stampfer M, Hu F, Franz M, Sampson L, Hennekens C \& Manson J (2000) A prospective study of dietary glycemic load, carbohydrate intake, and risk of coronary heart disease in US women. American Journal of Clinical Nutrition 71, 1455-1461.

Östman EM, Nilsson M, Liljeberg Elmståhl HGM, Molin G \& Björck IME (2002) On the effect of lactic acid on blood glucose and insulin responses to cereal products: mechanistic studies in healthy subjects and in vitro. Journal of Cereal Science 36, 335-342.

Salmerón J, Ascherio A, Rimm EB, Colditz GA, Spiegelman D, Jenkins DJ, Stampfer MJ, Wing AL \& Willett WC (1997a) Dietary fibre, glycemic load, and risk of NIDDM in men. Diabetes Care 20, 545-550.
Salmerón J, Manson JE, Stampfer MJ, Colditz GA, Wing AL \& Willett WC (1997b) Dietary fibre, glycemic load, and risk of non-insulin-dependent diabetes mellitus in women. Journal of the American Medical Association 277, 472-477.

Scheppach W, Sommer H, Kirchner T, Paganelli G-M, Bartram P, Cristl S, Richterj F, Dusel G \& Kasper H (1992) Effect of butyrate enemas on the colonic mucosa in distal ulcerative colitis. Gastroenterology 103, 51-56.

Thorburn A, Muir J \& Proitto J (1993) Carbohydrate fermentation lowers hepatic glucose output in healthy subjects. Metabolism 42, 780-785.

Venter CS, Vorster HH \& Cummings JH (1990) Effects of dietary propionate on carbohydrate and lipid metabolism in healthy volunteers. American Journal of Gastroenterology $\mathbf{8 5}$, 549-553.

Wolever TM, Brighenti F \& Royall D (1989) Effect of rectal infusion of short chain fatty acids in human subjects. American Journal of Gastroenterology 84, 1027-1037.

Wolever TM, Jenkins DJ, Jenkins AL \& Josse RG (1991) The glycemic index: methodology and clinical implication. American Journal of Clinical Nutrition 54, 846-854.

Wolever TM, Jenkins DJ, Ocana AM, Rao VA \& Collier GR (1988) Second-meal effect: low-glycemic-index foods eaten at dinner improve subsequent breakfast glycemic response. American Journal of Clinical Nutrition 48, 1041-1047. 